See Article page 182.

\section{Commentary: Stroke gives me confusion}

\author{
Carlos A. Mestres, MD, PhD, FETCS, ${ }^{\mathrm{a}, \mathrm{b}}$ and \\ Daniel Pereda, $\mathrm{MD}, \mathrm{PhD}^{\mathrm{c}}$
}

Stroke is a major complication after cardiac surgery with or without extracorporeal circulation ${ }^{1}$ and percutaneous coronary intervention. ${ }^{2}$ Ischemic stroke is challenging because its pathophysiology is multifactorial and may develop at any time during and after cardiac operations. Usually, intraoperative and immediate postoperative stroke are not related to an individual risk factor like carotid disease. With due controversy, perfusion pressure, ${ }^{3}$ preoperative atrial fibrillation, ${ }^{4}$ aortic atheroma,${ }^{5}$ combined intracardiac operations, ${ }^{6}$ and others may have an influence on stroke and outcomes.

The landmark contribution of Roach and colleagues ${ }^{7}$ determined the incidence of stroke after coronary artery bypass graft $(\mathrm{CABG})$ surgery and identified independent predictors of cerebral outcomes. There was an estimated $3.1 \%$ incidence of type I focal adverse cerebral outcomes with influence on mortality and disability. Twenty-five years later, premises of that study, risk factors, and ultimately outcomes are similar.

CABG is the most common operation in cardiac surgery even today with a risk of perioperative stroke of $1.3 \%$ to $1.4 \%$ or higher depending on statistics, ${ }^{8,9}$ the main problem being prevention. The value of preoperative imaging of the neck vessels and the brain has been studied in patients with multiple atheroma. ${ }^{10}$

Hess and colleagues ${ }^{11}$ retrospectively investigated the prevalence of concurrent severe carotid artery stenosis

\footnotetext{
From the ${ }^{a}$ Department of Cardiac Surgery, University Hospital Zürich, Zürich, Switzerland; 'bepartment of Cardiothoracic Surgery, The University of the Free State, Bloemfontein, South Africa; and ${ }^{\mathrm{c} D e p a r t m e n t}$ of Cardiovascular Surgery, Hospital Clinic, University of Barcelona, Barcelona, Spain.

Disclosures: Dr Mestres has received consulting fees from the Edwards Clinical Events Committee, and Cytosorbents Corp. Dr Pereda reported no conflicts of interest.

The Journal policy requires editors and reviewers to disclose conflicts of interest and to decline handling or reviewing manuscripts for which they may have a conflict of interest. The editors and reviewers of this article have no conflicts of interest.

Received for publication July 22, 2021; revisions received July 22, 2021; accepted for publication July 26, 2021; available ahead of print Aug 4, 2021.

Address for reprints: Carlos A. Mestres, MD, PhD, FETCS, Department of Cardiac Surgery, University Hospital Zürich, Rämistrasse 100, CH-8091 Zürich, Switzerland (E-mail: Carlos.Mestres@usz.ch).

JTCVS Open 2021;7:193-4

2666-2736

Copyright (C) 2021 The Author(s). Published by Elsevier Inc. on behalf of The American Association for Thoracic Surgery. This is an open access article under the CC BY-NC-ND license (http://creativecommons.org/licenses/by-nc-nd/4.0/).

https://doi.org/10.1016/j.xjon.2021.07.025
}

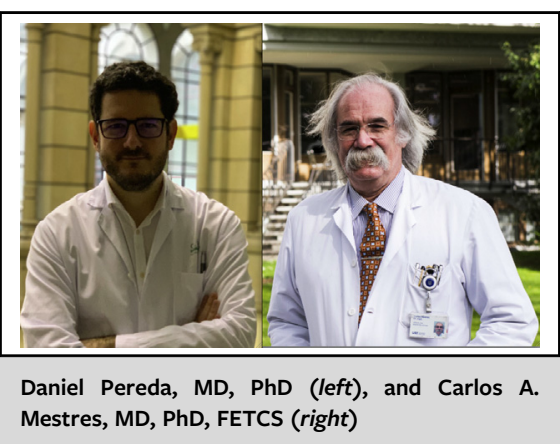

CENTRAL MESSAGE

Untreated severe carotid stenosis at the time of coronary surgery yields high perioperative stroke rate and lower 5-year survival. Perioperative stroke is unrelated to a carotid stenosis in $60 \%$.

(sCAS) at the time of CABG and its influence on perioperative and follow-up stroke. Stratification was based on $\geq 80 \%$ stenosis in at least 1 carotid artery evaluated with ultrasonography. Authors enrolled 5475 patients, $8.4 \%$ with and $91.6 \%$ without sCAS. Perioperative ischemic stroke rate was 3 times higher in sCAS, but only in $40 \%$ of cases could be anatomically related to the carotid stenosis detected. One- and 5-year survivals were lower in patients with sCAS. In multivariable analysis, sCAS was associated with increased risk-adjusted hazards for mortality and stroke, and the strongest risk-adjusted predictor for stroke was a prior history of stroke.

A couple of important facts have been identified. The first is the much higher perioperative stroke rate in patients with untreated sCAS, although in less than one-half of patients a specific carotid stenosis might have been related to the event. Second, the 5-year survival was also lower in the sCAS group, with previous cerebrovascular accidents playing a role. Authors confirmed then that the structural and temporal relationships between coronary disease requiring CABG, sCAS and stroke, are quite complex and, after many years of multiple preventing strategies, ${ }^{12}$ we still have questions to answer. With the understanding of the important intrinsic limitations of the study, such as being retrospective, the degree of carotid stenosis chosen or lack of information about the actual strategy for CABG (circulatory support and graft selection), the information produced by the authors challenges again which is the best 
preoperative surveillance for neck atherosclerosis in patients undergoing $\mathrm{CABG}$.

Patients in the sCAS group were older, were more frequently women and had a higher prevalence of chronic obstructive pulmonary disease, heart failure, and peripheral arterial disease. Moreover, with only $40 \%$ of the perioperative strokes related to a given carotid location, the data shown herein may challenge not only whether or not preCABG carotid revascularization may be beneficial, but also whether or not routine carotid ultrasound workup should be performed in the absence of symptoms. The topic is still open for discussion.

\section{References}

1. Lorusso R, Moscarelli M, Di Franco A, Grazioli V, Nicolini F, Gherli T, et al. Association between coronary artery bypass surgical techniques and postoperative stroke. J Am Heart Assoc. 2019;8:e013650.

2. Sawano M, Kohsaka S, Ishii H, Numasawa Y, Yamaji K, Inohara T, et al. Oneyear outcome after percutaneous coronary intervention for acute coronary syndrome - an analysis of 20,042 patients from a Japanese nationwide registry. Circ J. June 24, 2021 [Epub ahead of print].

3. Wiberg S, Holmgaard F, Blennow K, Nilsson JC, Kjaergaard J, Wanscher M. Associations between mean arterial pressure during cardiopulmonary bypass and biomarkers of cerebral injury in patients undergoing cardiac surgery: secondary results from a randomized controlled trial. Interact Cardiovasc Thorac Surg. 2021;32:229-35.

4. Hornero F, Martin E, Paredes F, Gil O, Cánovas S, García R, et al. Stroke after coronary artery bypass grafting: preoperative predictive accuracies of CHADS2 and CHA2DS2VASc stroke risk stratification schemes. J Thorac Cardiovasc Surg. 2012; 144:1428-35

5. Asenbaum U, Nolz R, Puchner SB, Schoster T, Baumann L, Furtner J, et al. Coronary artery bypass grafting and perioperative stroke: imaging of atherosclerotic plaques in the descending aorta with ungated high-pitch CT-angiography. Sci Rep. 2020;10:13909.

6. Schmitz C, Binder K, Bonatti JO, van Boven WJ, Glauber M, Mestres CA, et al. Intra-aortic filtration in cardiac surgery: an effective method to reduce neurologic injury in high-risk patients. Innovations (Phila). 2009;4:13-9.

7. Roach GW, Kanchuger M, Mangano CM, Newman M, Nussmeier N, Wolman R, et al. Adverse cerebral outcomes after coronary bypass surgery. Multicenter study of perioperative ischemia research group and the ischemia research and education foundation investigators. N Engl J Med. 1996;335: 1857-63.

8. Fernandez FG, Shahian DM, Kormos R, Jacobs JP, D’Agostino RS, Mayer JE Jr, et al. The Society of Thoracic Surgeons national database 2019 annual report. Ann Thorac Surg. 2019;108:1625-32.

9. Roy P, Brahme I, Reddy RP, Wechsler L, Gleason T, Thirumala PD. Meta-analysis of perioperative stroke and mortality in $\mathrm{CABG}$ patients with carotid stenosis. Neurologist. 2020;25:113-6.

10. Ali I, Shokri H, Abd Al Jawad M. Assessment of carotid artery stenosis and lower limb peripheral ischemia before coronary artery bypass grafting operations: a non-randomized clinical trial. J Cardiothorac Surg. 2020;15: 283.

11. Hess NR, Kilic A, Serna-Gallegos D, Navid F, Ferdinand FD, Wang Y, et al. Effect of untreated carotid artery stenosis at time of isolated coronary artery bypass grafting. J Thorac Cardiovasc Surg Open. 2021;7:182-90.

12. Gaudino M, Benesch C, Bakaeen F, DeAnda A, Fremes SE, Glance L, et al; American Heart Association Council on Cardiovascular Surgery and Anesthesia; Stroke Council; and Council on Cardiovascular and Stroke Nursing. Considerations for reduction of risk of perioperative stroke in adult patients undergoing cardiac and thoracic aortic operations: a scientific statement from the American Heart Association. Circulation. 2020;142:e193-209. 